\title{
Sosialisasi Website Portal Bank Sampah Universitas Lancang Kuning
}

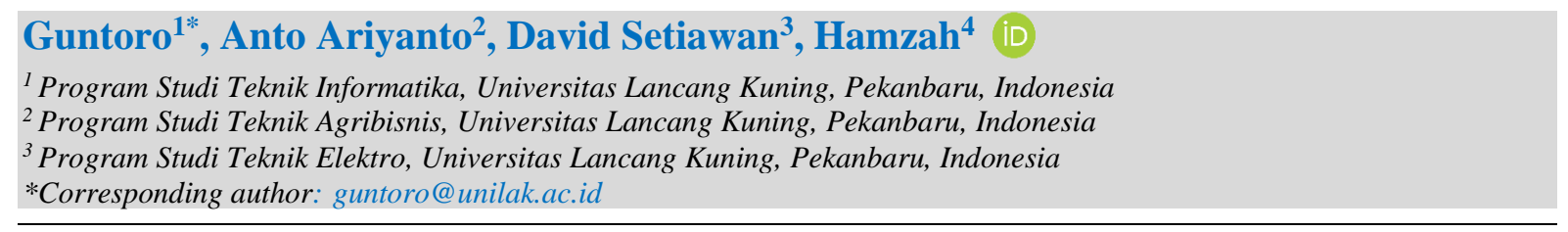

\begin{abstract}
Abstrak
Kehadiran sampah merupakan salah satu persoalan yang dihadapi oleh masyarakat. Sampah adalah material sisa dari aktivitas manusia yang tidak memiliki keterpakaian, akibatnya sampah dapat menimbulkan kerugian karena akan menyebabkan banjir, meningkatnya pemanasan iklim, menimbulkan bau busuk, mengganggu keindahan, memperburuk sanitasi lingkungan. Salah satu cara untuk mengumpulkan sampah agar bernilai ekonomis ialah melalui bank sampah. Penelitian ini bertujuan untuk menghasilkan sistem informasi website Bank Sampah sehingga dapat memudahkan bagi pengelola untuk menyebarkan informasi serta masyarakat dapat mencari informasi dengan lebih mudah. Metode yang digunakan pada penelitian pengabdian ini adalah menggunakan metode waterfall. Ada beberapa tahapan yang dilakukan yaitu analisa kebutuhan, perancangan, implementasi dan pengujian, serta pemeliharaan. Hasil penelitian pengabdian ini menunjukkan bahwa aplikasi yang dibangun dapat memberikan informasi terkait Bank Sampah berbasis web, aplikasi yang dibangun dapat memberikan fasilitas serta kemudahan bagi pengelola Bank Sampah untuk menyeberkan informasi kegiatan, masyarakat dapat dengan mudah mencari informasi terkait Bank Sampah, masyarakat dapat memberikan komentar atau masukan terkait dengan Bank Sampah.
\end{abstract}

Kata Kunci: Sosialisasi, Bank Sampah, Website

\section{Abstract}

The presence of waste is one of the problems faced by the community. Garbage is residual material from human activities that has no use, as a result, waste can cause losses because it will cause flooding, increase climate warming, cause bad smells, disturb beauty, worsen environmental sanitation. One way to collect waste so that it has economic value is through a waste bank. This study aims to produce an information system on the Waste Bank website so that it can make it easier for managers to disseminate information and the public can find information more easily. The method used in this service research is using the waterfall method. There are several stages carried out, namely needs analysis, design, implementation and testing, and maintenance. The results of this service research show that the application built can provide information related to the web-based Waste Bank, the application built can provide facilities and convenience for Waste Bank managers to disseminate activity information, the public can easily find information related to the Waste Bank, the public can provide comments or feedback related to Waste Bank.

Keywords: Socialization, Waste Bank, Website

\section{INTRODUCTION}

Teknologi informasi merupakan faktor pendukung yang sangat efektif yang memungkinkan masyarakat untuk menikmati berbagai kemudahan yang diberikan oleh teknologi (Boström \& Micheletti, 2016; Claxton \& Kent, 2020; Manavalan \& Jayakrishna, 2019). Teknologi banyak digunakan sebagai sarana promosi dan informasi, khususnya di bidang website, yang kini berperan penting dalam penyampaian informasi. Website dapat memberikan informasi yang lebih efisien dan up-to-date. Masyarakat di berbagai daerah kini dapat mengakses website dengan lebih mudah dengan menggunakan internet. Website misalnya dapat digunakan untuk media pemasaran, informasi, edukasi, komunikasi, dan promosi. Website merupakan salah satu teknologi internet tidak hanya sebagai media informasi

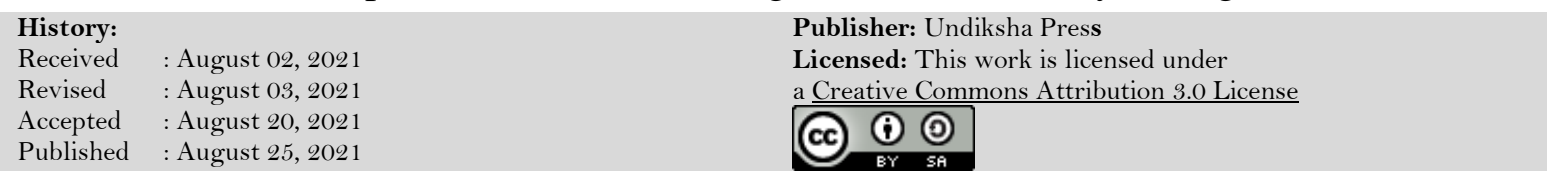


tetapi menjadi proses pendukung bisnis perusahaan seperti penjualan produk dan jasa secara online (Bernstein et al., 2021; Rusdi et al., 2017). Website bisa diakses oleh semua orang diberbagai wilayah dengan menggunakan jaringan internet. Sebuah halaman website mempunyai informasi dokumen-dokumen seperti text, gambar, suara, video menggunakan protokol HTTP (hypertext transfer protokol). Banyak fitur yang bisa dimanfaatkan pada sebuah halaman website yaitu sebagai media informasi dan promosi sebuah produk atau jasa. Salah satu promosi produk yaitu bank sampah Universitas Lancang Kuning.

Bank Sampah Universitas Lancang Kuning adalah salah satu Bank Sampah yang berada di lingkungan kampung Universitas Lancang Kuning Pekanbaru Riau. Tujuan bank sampah Universitas Lancang Kuning adalah menjadi media agar masyarakat sadar akan menjaga lingkungan dan dapat meningkatkan kesejahteraan masyarakat khususnya bagi nasabah. Demi tercapainya tujuan bank sampah Universitas Lancang Kuning, pengelola bank sampah harus memperhatikan masalah pengelolaan informasi khususnya nasabah serta masyarakat pada umumnya. Bank sampah telah dilaunching pada tanggal 29 Maret 2021 tetapi bank sampah ini belum memiliki media informasi website. Media informasi berupa website ini mampu menjadi media promosi agar tujuan bank sampah dapat tercapai dengan maksimal. Selama ini pemasaran bank sampah masih dilakukan secara offline. Dampak pemasaran dan promosi dengan sistem offline yaitu jangkauan terbatas, sehingga belum diketahui oleh masyarakat luas. Maka diperlukan sebuah website untuk promosi bank sampah tersebut.

Sistem pengelolaan bank sampah sama seperti lembaga perbankan. Perbedaaanya, jika dalam perbankan yang disetorkan atau yang ditukarkan adalah uang, dalam bank sampah yang ditukarkan adalah sampah. Sampah akan ditukarkan dengan uang yang kemudian dicatat dalam buku rekening. Sama halnya lembaga perbankan, dalam bank sampah juga dikenal adanya nasabah. Nasabah merupakan masyarakat yang menyetorkan sampah kemudian mendapatkan rekening sebagai buku perhitungan akumulasai jumlah normal yang diperoleh. Konsep pengelolaan sampah yang dilakukan di bank sampah adalah penerapan dari konsep zero waste yakni pendekatan serta penerapan system teknologi pengolahan sampah perkotaan skala kawasan secara terpadu dengan melakukan penanganan sampah dengan tujuan dapat mengurangi sampah sedikit mungkin (Dwiputri \& Albarda, 2017; Nuraenah et al., 2016). Konsep ini merupakan konsep pengelolaan sampah yang sesuai dengan apa yang diamanatkan dalam Undang-Undang Nomor 18 Tahun 2008, yaitu pengelolaan sampah melalui pendekatan reduse, reuse, dan recycle atau sering dikenal dengan $3 \mathrm{R}$.

Beberapa penelitian yang relevan dengan penelitian ini seperti penelitian yang dilakukan oleh (Ardhiyani \& Mulyono, 2018) menyatakan bahwa perancangan berupa sitem informasi pariwisata berbasis web yang diharapkan mampu menjadi sebuah media yang dapat mempromosikan wisata Kabupaten tebo selanjutnya dengan adanya perancangan desain web ini diharapkan adanya proses perancangan serupa untuk menghasilkan karya yang lebih baik dan lebih lengkap dari karya yang ada. Kemudian penelitian yang dilakukan oleh (Purwati et al., 2021) menyatakan bahwa Dengan membuat website layanan Sampling (Sampah Lingkungan) dapat memudahkan pelanggan jika akan melakukan pembelian ataupun menggunakan layanan jasa pembuatan produk. Tujuan penelitian ini adalah untuk menghasilkan sistem informasi website Bank Sampah Universitas Lancang Kuning, sehingga dapat memudahkan bagi pengelola untuk menyebarkan informasi serta masyarakat dapat mencari informasi dengan lebih mudah.

\section{MATERIALS AND METHODS}

Metode yang digunakan pada pengabdian ini adalah menggunakan metode waterfall. Metode waterfall merupakan salah satu metode yang digunakan untuk pengembangan perangkat lunak yaitu dilakukan secara berurutan maupun secara sekuansial. Ada beberapa 
tahapan yang dilakukan yaitu analisa kebutuhan, perancangan, implementasi dan pengujian, serta pemeliharaan. Adapun tahapannya terlihat pada Gambar 1.

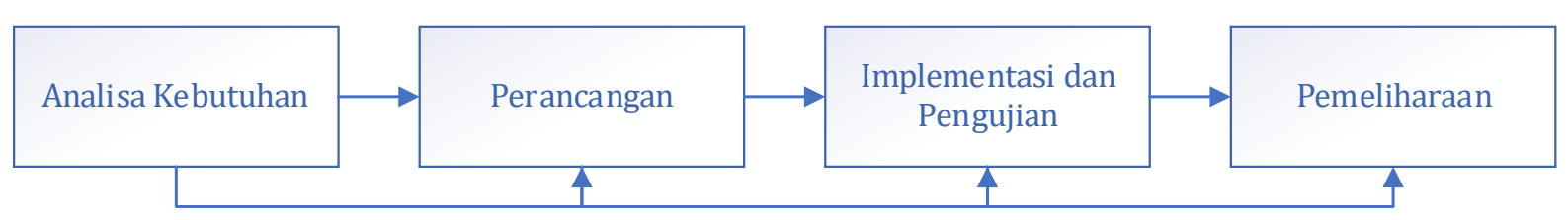

Gambar 1. Tahapan Pengembangan Sistem

Pada langkah Analisa kebutuhan ini merupakan tahap pengumpulan data dan informasi yang dibutuhkan untuk pengembangan website bank sampah, sehingga bisa dilakukan analisa. Hasil analisa ini nantinya akan dijadikan sebagai acuan untuk perancangan sistem. Sebelum melakukan perancangan sistem, diperlukan informasi yang jelas mengenai sistem yang akan dibangun, tujuannya adalah agar dapat memperoleh gambaran umum mengenai prosedur kerja website bank sampah Universitas Lancang Kuning. Dalam hal ini dilakukan teknik pengumpulan data yang berkaitan dengan bank sampah. Adapun analsa kebutuhan sistem meliputi perangkat keras untuk pengembangan website Bank Sampah, berikut perangkat keras yang digunakan adalah Laptop Lenovo Thinkpad T430 Processor i5, RAM 8 GB, Hardisk 240 GB, dan perangkat lunak untuk kebutuhan perangkat lunak pendukung dalam pengembangan website Bank Sampah yaitu sistem Operasi Windows 10 Pro, Bahasa Pemrograman PHP, Framework Codeigniter, Xampp, Notepad++, Microsoft Visio 2019.

Sebelum sistem dilakukan implementasi, tahapan yang dilakukan adalah melakukan perancangan sistem dengan menggunakan pemodelan Flow Chart dan Data Flow Diagram (DFD). Pada tahap Implementasi dan Pengujian ini akan dilakukan implementasi sistem dengan menggunakan bahasa pemrograman PHP, HTML, Boostrap. Adapun tahap pengujian dilakukan untuk menguji apakah sistem yang dibangun dapat berjalan dengan baik atau tidak. Pengujian dilakukan terhadap dua aspek yaitu aspek fungsionalitas dan aspek penanganan kesalahan. Aspek fungsionalitas diuji berdasarkan use case yang telah ditetapkan sebelumnya, sedangkan aspek penanganan kesalahan bertujuan untuk mengetahui kesalahan-kesalahan yang terjadi.

\section{RESULTS AND DISCUSSION}

\section{Hasil}

\section{Perancangan Sistem}

Dalam perancangan konteks diagram, ditunjukkan fungsionalitas sistem serta bagaimana sistem berinteraksi di luar sistem. Konteks diagram digunakan untuk menggambarkan hubungan antara sistem dengan luar sistem. Website Bank Sampah Universitas Lancang Kuning ini memiliki 2 entitas yaitu pengguna dan pengelola (admin). Adapun gambaran konteks diagramnya seperti terlihat pada Gambar 2 dan hasil implementasi website bank sampah terlihat pada Gambar 3. Profil bank sampah dapat dilihat pada Gambar 4, dan halaman administrator dapat dilihat pada Gambar 5. 

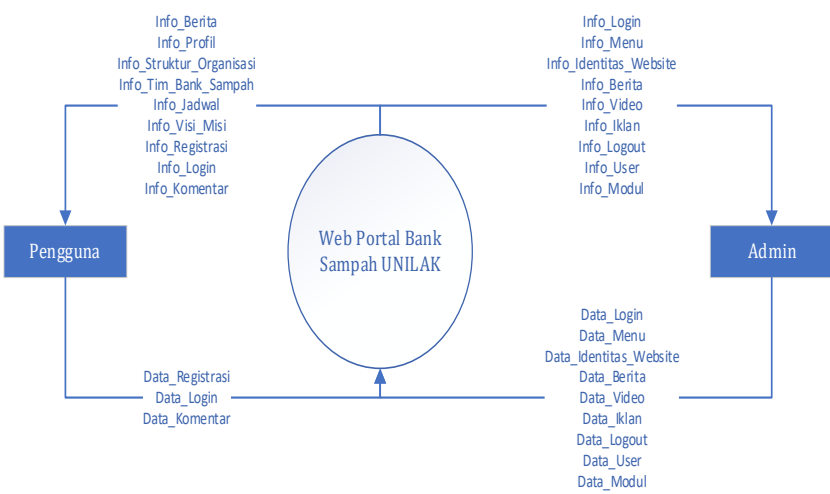

Gambar 2. Perancangan Sistem

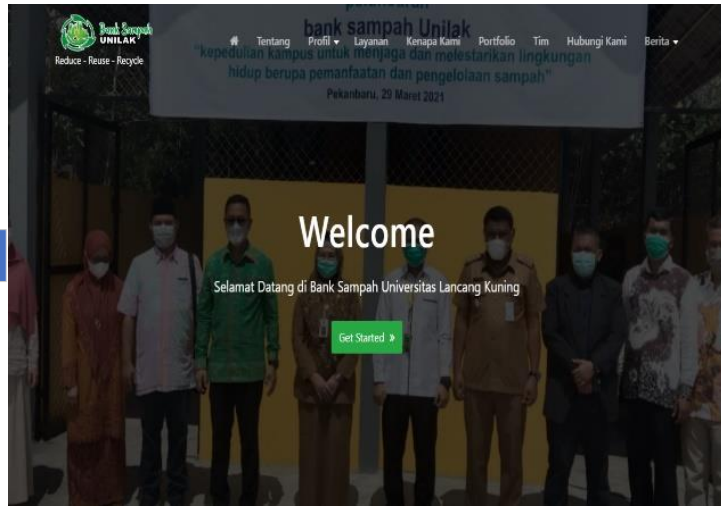

Gambar 3. Website Bank Sampah Universitas Lancang Kuning

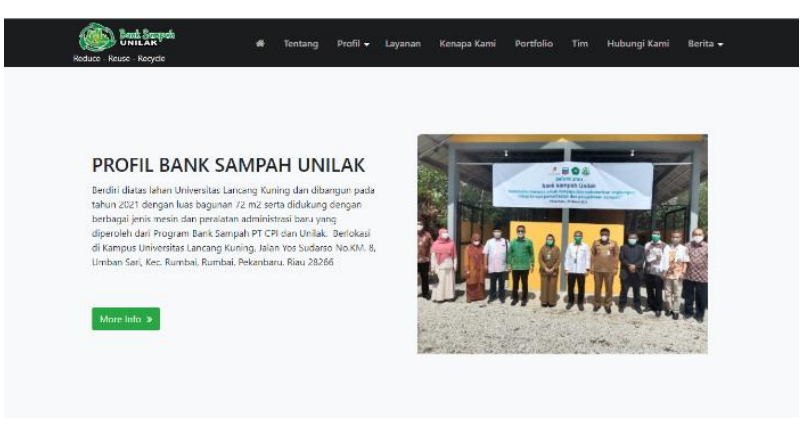

Gambar 4. Halaman Profil

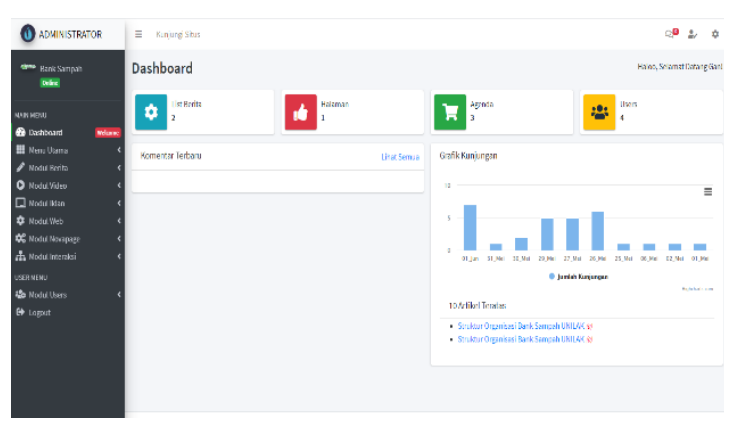

Gambar 5. Halaman Administrator

Kehadiran sampah merupakan salah satu persoalan yang dihadapi oleh masyarakat. Sampah adalah material sisa dari aktivitas manusia yang tidak memiliki keterpakaian, akibatnya sampah dapat menimbulkan kerugian karena akan menyebabkan banjir, meningkatnya pemanasan iklim, menimbulkan bau busuk, mengganggu keindahan, memperburuk sanitasi lingkungan (Dwiputri \& Albarda, 2017; Fajriya, 2020; A. S. Suryani, 2014). Semakin banyak limbah sampah di lingkungan masyarakat sehingga sebagian masyarakat menjadikan aktivitas kebiasaan membuang sampah dengan sembarangan, karena kurangnya kesadaran dan pengetahuan masyarakat dalam memanfaatkan limbah sampah. Kesempatan ini menjadi peluang bagi pengusaha peduli lingkungan untuk memanfaatkan limbah sampah khususnya limbah sampah an- organik, dengan cara mendaur ulang sampah yang di kumpulkan dari masyarakat kemudian diolah menjadi suatu barang yang memiliki nilai jual. Salah satu cara mengumpulkan sampah dapat dilakukan melalui Bank Sampah.

Bank Sampah merupakan tempat menabung sampah yang telah terpilah menurut jenis sampah (Kusuma Wardany et al., 2020; Saputro et al., 2015; E. Suryani, 2016). Cara kerja Bank Sampah pada umumnya hampir sama dengan bank lainnya, ada nasabah, pencatatan pembukuan dan manajemen pengelolaannya. Apabila dalam bank umum yang disetorkan nasabah adalah uang, akan tetapi dalam Bank Sampah yang disetorkan adalah sampah yang mempunyai nilai ekonomis (Asteria \& Heruman, 2016; Nugraheni \& Widyaningrum, 2019). Bank sampah sebaiknya dikelola oleh orang yang kreatif dan inovatif, serta memiliki jiwa kewirausahaan, agar dapat meningkatkan pendapatan masyarakat. Sistem kerja Bank Sampah dilakukan berbasis rumah tangga, dengan memberikan reward kepada yang berhasil memilah dan menyetorkan sejumlah sampah. Konsep Bank Sampah mengadopsi menajemen bank pada umumnya. Selain bisa sebagai sarana untuk melakukan gerakan penghijauan, pengelolaan sampah juga bisa menjadi sarana pendidikan gemar menabung untuk masyarakat dan anak- 
anak. Metode Bank Sampah juga berfungsi untuk memberdayakan masyarakat agar peduli terhadap kebersihan

Bank Sampah memiliki beberapa manfaat bagi manusia dan lingkungan hidup, seperti membuat lingkungan lebih bersih, menyadarkan masyarakat akan pentingnya kebersihan, dan membuat sampah menjadi barang ekonomis. Sampah-sampah yang disetorkan ke bank sampah dibedakan menjadi beberapa jenis, misalnya: sampah organik, seperti potongan sayuran atau sisa masakan; mapun nonorganik seperti plastik, besi, dan lainnya. Bank Sampah menetapkan harga beli untuk masing-masing jenis sampah tersebut. Sampah yang masih dapat di daur ulang seperti bahan organik dapat dimanfaatkan untuk kompos ataupun biogas. Sedangkan bahan nonorganik didaur ulang menjadi berbagai perabotan seperti tas, sendal, dan lainnya. Adanya website bank sampah ini untuk memberikan memberikan fasilitas serta kemudahan bagi pengelola Bank Sampah Universitas Lancang Kuning untuk menyeberkan informasi kegiatan. Masyarakat dapat dengan mudah mencari informasi terkait Bank Sampah Universitas Lancang Kuning. Masyarakat dapat memberikan komentar atau masukan terkait dengan Bank Sampah Universitas Lancang Kuning.

\section{CONCLUSION}

Aplikasi yang dibangun dapat memberikan informasi terkait Bank Sampah Universitas Lancang Kuning berbasis web. Aplikasi yang dibangun dapat memberikan fasilitas serta kemudahan bagi pengelola Bank Sampah Universitas Lancang Kuning untuk menyeberkan informasi kegiatan. Masyarakat dapat dengan mudah mencari informasi terkait Bank Sampah Universitas Lancang Kuning. Masyarakat dapat memberikan komentar atau masukan terkait dengan Bank Sampah Universitas Lancang Kuning.

\section{REFERENCES}

Ardhiyani, R. P., \& Mulyono, H. (2018). Analisis Dan Perancangan Sistem Informasi Pariwisata Berbasis Web Sebagai Media Promosi Pada Kabupaten Tebo. Jurnal Manajemen Sistem Informasi, 3(1), 952-972. https://doi.org/http://dx.doi.org/10.3112/speed.v3i4.1155.

Asteria, D., \& Heruman, H. (2016). Bank Sampah Sebagai Alternatif Strategi Pengelolaan Sampah Berbasis Masyarakat di Tasikmalaya. Jurnal Manusia Dan Lingkungan, 23(1), 136. https://doi.org/https://doi.org/10.22146/jml.18783.

Bernstein, M. T., Reynolds, K. A., Jakobson, L. S., Petty, S. K., Pryor, T. A. M., Stoesz, B. M., Alcolado, G. M., \& Furer, P. (2021). Do anxiety websites have the answers people are looking for? Patient Education and Counseling, xxxx, 0-1. https://doi.org/10.1016/j.pec.2021.08.002.

Boström, M., \& Micheletti, M. (2016). Introducing the Sustainability Challenge of Textiles and Clothing. Journal of Consumer Policy, 39(4), 367-375. https://doi.org/10.1007/s10603-016-9336-6.

Claxton, S., \& Kent, A. (2020). The management of sustainable fashion design strategies: An analysis of the designer's role. Journal of Cleaner Production, 268, 122112. https://doi.org/10.1016/j.jclepro.2020.122112.

Dwiputri, T., \& Albarda, A. (2017). Sistem Informasi Manajemen Limbah Untuk Simbiosis Usaha Tani dan Ternak. Jurnal Edukasi Dan Penelitian Informatika (JEPIN), 3(2), 8288. https://doi.org/http://dx.doi.org/10.26418/jp.v3i2.22761.

Fajriya, H. (2020). Manajemen Pemasaran Pada Bank Sampah Syariah Secara Bertahap, Berkesinambungan dan Sistematis. Al-Musthofa: Journal of Sharia Economics, 3(1). https://ejournal.iai-tabah.ac.id/index.php/musthofa/article/view/530. 
Kusuma Wardany, Reni Permata Sari, \& Erni Mariana. (2020). Sosialisasi Pendirian "Bank Sampah" Bagi Peningkatan Pendapatan Dan Pemberdayaan Perempuan Di Margasari. Dinamisia: Jurnal Pengabdian Kepada Masyarakat, 4(2), 364-372. https://doi.org/10.31849/dinamisia.v4i2.4348.

Manavalan, E., \& Jayakrishna, K. (2019). A review of Internet of Things (IoT) embedded sustainable supply chain for industry 4.0 requirements. Computers and Industrial Engineering, 127, 925-953. https://doi.org/10.1016/j.cie.2018.11.030.

Nugraheni, Y., \& Widyaningrum, A. Y. (2019). Dinamika Sikap Warga atas Program CSR Bank Sampah Gunung Anyar Surabaya. Jurnal Studi Komunikasi (Indonesian Journal of Communications Studies), 3(1), 41. https://doi.org/10.25139/jsk.v3i1.1419.

Nuraenah, N., Novalina, K., \& Deviarni, I. M. (2016). Ibm Pengembangan Produk Berbasis Lele Dengan Konsep Zero Waste Process Di Kelurahan Sungai Jawi Kecamatan Pontianak Kota, Kota Pontianak. Jurnal Teknologi Pangan, 7(2), 68-73. https://doi.org/https://doi.org/10.35891/tp.v7i2.507.

Purwati, N., Dwitama, F. N., \& Kiswati, S. (2021). Aplikasi Sampling (Sampah Lingkungan) Pengrajin Sampah Berbasis Web Menggunakan Metode RAD (Rapid Application Development). EVOLUSI: Jurnal Sains Dan Manajemen, 9(1), 78-86. https://doi.org/10.31294/evolusi.v9i1.10316.

Rusdi, R., Sahari, N., \& Noor, S. F. M. (2017). Usability Guidelines For Elderly Website Interface Rasyiqah. Jurnal Teknologi Maklumat Dan Multimedia Asia-Pasifik, 6(2), 109-122. https://doi.org/https://doi.org/10.17576/apjitm-2017-0602-10.

Saputro, Y. E., Kismartini, K., \& Syafrudin, S. (2015). Pengelolaan Sampah Berbasis Masyarakat Melalui Bank Sampah. Indonesian Journal of Conservation, 4(1), 83-94. https://doi.org/https://doi.org/10.15294/ijc.v4i1.5162.

Suryani, A. S. (2014). Peran Bank Sampah Dalam Efektivitas Pengelolaan Sampah (Studi Kasus Bank Sampah Malang). Jurnal Aspirasi, 5(1), 71-84. https://doi.org/https://doi.org/10.46807/aspirasi.v5i1.447.

Suryani, E. (2016). Manajemen Pengelolaan Bank Sampah di Kota Bekasi. JAKP Jurnal Administrasi Dan Kebijakan Publik, 6(1), 63-75. https://doi.org/https://doi.org/10.33558/akp.v6i1.584. 